\title{
A Study of Compact Branch Line Coupler
}

\author{
Vijay Jutru $^{\mathrm{a}, 1}$, and Maheswari $\mathrm{S}{ }^{\mathrm{b}}$ \\ ${ }^{a} P G$ Scholar , Dept of ECE ,Panimalar Engineering College, Chennai \\ ${ }^{b}$ Professor Dept of ECE ,Panimalar Engineering College, Chennai
}

\begin{abstract}
In this paper we analyze various structures of branch line coupler with different frequencies of $1 \mathrm{GHz}$ to $2.5 \mathrm{GHz}$. .Couplers are used for splitting or combining power. It is basically a $3 \mathrm{~dB}$ power divider or combiner with symmetrical four port network for obtaining $90^{\circ}$ phase difference between its output.It has been used in many applications such as in mixers, power amplifiers, modulators, anteena beam forming networks. The major advantages of branch line coupler are low profile, easy to fabricate, light weight.
\end{abstract}

Keywords: Branch line coupler, compact size, transmission lines, coupling lines, planar circuits

\section{Introduction}

A branch line couplers were widely used for many microwave applications and integrated circuits like as amplifiers, and phase shifters balanced mixers [1]. It can be used as a power divider/combiner or a part of a mixer. At the low frequency size of the coupler is large. Branchline couplers are often developed as stripline or microstrip forms. Symmetry of high degree is obtained by placing any port as a single port and the input port is used as isolation port on the another side of the junction from input port and output port is used. The $90^{\circ}$ phase difference changes over \pm 50 for a $10 \%$ change in frequency around the operating frequency. Passive components are found in the millimetre-wave \& microwave circuits was branchline coupler and rat race ring coupler. The branch line and rat-race ring couplers [1] are consist of four or six quarter-wavelength transmission-line section. There are multiple methods available to reduced size of the couplers[2,10],such as lumped object [2], stubs with open end [3], slow wave structure with discontinuous microstrip[4], patch with T slot.

\section{Related Works}

Bing-Zhong Wang et.al [1] have designed a small sized branch line coupler with meander slot having higher impendace transmission line with its matching port. This paper focuses on a high port impedance and also on impedance matching. A compact branch line coupler operates at the frequency of $1.0 \mathrm{GHz}$ and the bandwidth obtained $10 \%$. The measured $S_{11}$ and $S_{41}$ are lower than $-25 \mathrm{~dB}$, the phase variation is greater than $5^{0}$ and the magnitude variation is greater than $0.65 \mathrm{~dB}$. The simulated $\mathrm{S}$ parameter

\footnotetext{
${ }^{1}$ Vijay Jutru, PG Scholar, Dept of ECE ,Panimalar Engineering College, Chennai, India. Email.vjy7070@gmail.com
} 
$\mathrm{S}_{21}$ and $\mathrm{S}_{31}$ are $-3.1 \&$-3.6dB.In this paper, incompatibility of ring as and branch-line coupler asymmetric structures is clarified then the design formulas of model symmetric equivalent circuits are obtained. Based on the derived formulas equivalent circuits were designed for coupled-line ring and branch-line couplers. For the improvement of equivalent circuits we used some techniques which were called as SC , SMT, and SM.

Sudini Reshma et.al [2] has proposed a small size hybrid coupler obtained wider bandwidth compared to traditional coupler. This technique is used to improve the coupling between the branches in order to provide higher bandwidth Figure.1 shows the equivalent circuit of the coupler. This coupler uses single band for compact structure.it operates at the frequency of $1.0 \mathrm{GHz}$ the measured insertion and return losses are better than $-15 \mathrm{~dB}$. The simulated $\mathrm{S}_{21} / \mathrm{S}_{31}$ are $-3.5 /-3.6 \mathrm{~dB}$. Therefore the phase difference between the two output port is $88^{\circ}$.

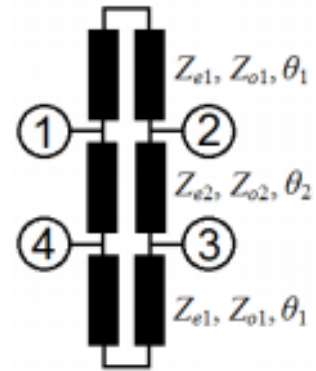

(a)

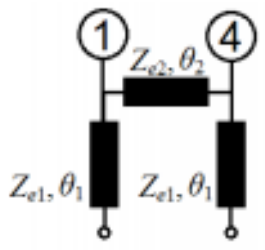

(b)

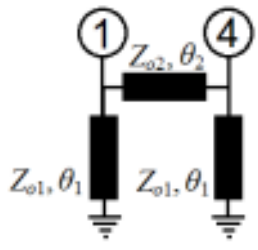

(c)

Figure 1. (a) Equivalent circuit of the coupler (b) even mode and (c) odd-mode excitation

Yongqiang Wang et.al [3] has implemented a novel small sized branch line coupler using Substrate Integrated Suspended Line(SISL) technology in order to reduce the size of the traditional coupler which consist of high low impedance line combined in meander structure. The SISL coupler has advantage of self packaging, low cost and light weight.the operating frequency is from 1.36 to $1.67 \mathrm{GHz}$. The simulated $\mathrm{S}_{21} / \mathrm{S}_{31}$ are -3.85/-3.75 and obtain the phase difference of $90{ }^{0}$.B.F.zong et.al [4] proposed a planar branch line coupler using the different characteristic impedance.Planar branch line coupler operating at $0.875 \mathrm{GHz}$ and also exhibit a stopband from 2.8 to $12.9 \mathrm{GHz}$. for higher rank harmonic suppression. The dimensions are $23.28 \times 2.28 \mathrm{~mm}$ and return loss obtained is $-20 \mathrm{~dB}$. The overall size of the coupler reduced to $17.6 \%$ compared to its traditional coupler. The bandwidth obtained for $0.875 \mathrm{GHz}$ coupler obtained is $3 \mathrm{~dB}$ at its transmission coefficients. The stop bandwidh ranges from 2.8 to $12.9 \mathrm{GHz}$ with reflection coefficient of $-20 \mathrm{~dB}$.

C.H.Tseng et.al[5] developed a small sized branch line coupler by using $\pi$ equivalent transmission lines with artificial transmission line based on shunt stub .The operating frequency is $0.9 \mathrm{GHz}$. The measured insertion \& return losses are -3.2 and $-3.7 \mathrm{~dB}$. The phase difference is $90^{\circ}$. The realtive bandwith is $16 \%$. 


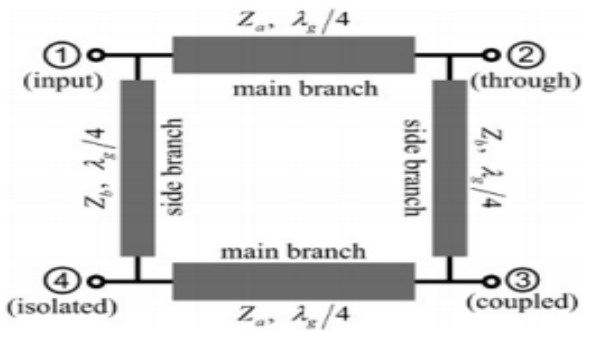

Figure 2. Circuit schematic of a branch-line coupler

The circuit schematic of a conventional branch-line coupler is represented in Figure.2. The structured branch line coupler the $Z_{A}$ and $Z_{B}$ represents the characteristic impedance $Z_{0}$ whereas the wavelength of $Z_{A}$ and $Z_{B}$ represent the quarter wavelength transmission line $(\lambda / 4)$. The two output ports 2 and 3 with the phase difference of 90 degree will be split into an input signal incident on the port 1.

Kai-Yu Tsai et.al[6] proposed a small sized branchline coupler $3 \mathrm{~dB}$ by using second harmonic transmission line with high impedance. Beside using the intergrated capacitor, shunt is used.Therefore the size reduction of $3 \mathrm{~dB}$ branchline coupler obtained and compararing with the existing system. The reduced size is $73.2 \%$ without degradation of preformance comparing with traditional coupler. The detailed $3 \mathrm{~dB}$ hybrid branchline coupler contains a second harmonic ability to supress and discontinuity of phase to achive frequency selectiveness .

W.-L. Chen et.al[7] proposed small sized branch-line couplers with fractalshaped. Due to different phase shifting properties of the fractal shaped microstrip lines the fracted shaped branch line couplers bandwidth is reduced and shifted .The measured results show that the overall size of the fractal-shaped coupler reached a maximum $81.8 \%$ reduction compared to traditional. The modern technique can be applied to other fractal designs having phase-shifting effects.

Ching-Wen Tang et.al[8] proposed dual transmission lines of the quarter wavelength in transmission lines were microstrip branch line coupler. Modified coupler will be quickly implemented on the PCB without using a lumped object, the size has been hugely compressed comparing in between the traditional branch line coupler. The responding impedances can be obtained by using the transmission lines, a reduced planar branch line coupler were design at a range of $2.4 \mathrm{GHz}$ as the resonance frequency. In proposed design size reduced is $63.9 \%$

Ching-Wen Tang et.al [9] proposed New design of microstrip branchline coupler with reduced size and bandwidth. Using microstrip branchline coupler, the distance of quarter wavelength transmission line with in the branch line connectorisreduced.Bythis process the branch line coupler can be reduced with four pa rts of the quarter wavelength transmission lines. By this method using equivalent quarter wavelength transmission lines and 6 small sized branch line connectors are developed at the frequency of $2.4 \mathrm{GHz}$. The corresponding design equations are explained in ideal no-loss conditions.

Jianpeng Wang et.al[10] proposed the slow wave microstrip branch line coupler is to decrease the occupied area upto $28 \%$ of the branch line coupler at 
the operating frequency 2.0 GHz. It contains a high performance of second harmonic suppression. A slow wave branch line connector is represented because of the high slow wave the size is decreased upto $28 \%$ of the conventional case at the frequency of 2.0 GHz. A sample branch line coupler shall be introduced, measured and compared to the standard one. Achieved bandwidth is $200 \mathrm{MHz}$ with phase difference of $90^{\circ}$.

\section{Literature survey}

Table 1. Design Specification for different couplers

\begin{tabular}{|c|c|c|c|c|c|}
\hline $\begin{array}{l}\text { S } \\
\text { No }\end{array}$ & $\begin{array}{l}\text { Operating } \\
\text { Frequency }\end{array}$ & $\begin{array}{c}\text { Bandwidt } \\
\mathrm{h}\end{array}$ & Substrate & $\begin{array}{l}\text { Dielectri } \\
\mathrm{c} \\
\text { Constant }\end{array}$ & Thickness \\
\hline [1] & $1.0 \mathrm{GHz}$ & $10 \%$ & $\mathrm{~F}_{4} \mathrm{~B}$ & 2.65 & $1.5 \mathrm{~mm}$ \\
\hline [2] & $1.0 \mathrm{GHz}$ & $33 \%$ & $\mathrm{FR}_{4}$ & 4.4 & $1.58 \mathrm{~mm}$ \\
\hline [3] & $\begin{array}{c}1.38- \\
1.7 \mathrm{GHz}\end{array}$ & & $\mathrm{FR}_{4}$ & 4.4 & $0.6 \mathrm{~mm}$ \\
\hline [4] & $0.87 \mathrm{GHz}$ & $27 \%$ & - & - & - \\
\hline [5] & $1 \mathrm{GHz}$ & $50 \%$ & Duroid 5800 & 2.2 & $0.787 \mathrm{~mm}$ \\
\hline [6] & $0.9 \mathrm{GHz}$ & $16.2 \%$ & Rogers R04003 & - & $0.508 \mathrm{~mm}$ \\
\hline [7] & $\begin{array}{c}836.5 \mathrm{MH} \\
\mathrm{z}\end{array}$ & $20 \%$ & $\mathrm{FR}_{4}$ & 4.22 & $40 \mathrm{~mm}$ \\
\hline [8] & $2.4 \mathrm{GHz}$ & $56 \%$ & $\begin{array}{c}\text { Duroid } \\
\text { 5800/Rogers } \\
\text { RT }\end{array}$ & 2.2 & $0.127 \mathrm{~mm}$ \\
\hline [9] & $2.4 \mathrm{GHz}$ & - & Rogers R04003 & 3.38 & $\begin{array}{c}0.0027 \mathrm{~m} \\
\mathrm{~m}\end{array}$ \\
\hline $\begin{array}{c}{[10} \\
]\end{array}$ & $\begin{array}{c}2.23- \\
2.53 \mathrm{GHz}\end{array}$ & $54.5 \%$ & $\mathrm{FR}_{4}$ & 4.4 & $\begin{array}{c}0.0182 \mathrm{~m} \\
\mathrm{~m}\end{array}$ \\
\hline
\end{tabular}

The analysis of various coupler has been discussed and shown in Table 1 with its operating frequency, bandwidth, substrate materials, dielectric constant and thickness of each paper is compared. from the above table we assume that $\mathrm{FR}_{4}$ is a low cost and light weight substrate material when compared to other substrate materials[11,12].

Table 2. Performance result of various coupler designs

\begin{tabular}{|c|c|c|c|c|c|c|}
\hline $\begin{array}{c}\mathrm{S} \\
. \text { No }\end{array}$ & $\begin{array}{c}\text { Impedance } \\
\mathrm{S} \\
(\Omega)\end{array}$ & $\mathrm{S}_{11}$ & $\mathrm{~S}_{41}$ & $\mathrm{~S}_{21}, \mathrm{~S}_{31}$ & $\begin{array}{c}\text { Phase } \\
\text { Differenc } \\
\mathrm{e} \\
(0)\end{array}$ & $\begin{array}{c}\text { Size } \\
\text { reductio } \\
\mathrm{n}\end{array}$ \\
\hline$[1]$ & $50 / 35.35 \Omega$ & $-25 \mathrm{~dB}$ & $-25 \mathrm{~dB}$ & $-3.1 /-3.6$ & $90^{0}$ & $29.1 \%$ \\
\hline$[2]$ & $50 / 35.35 \Omega$ & $-15 \mathrm{~dB}$ & $-20 \mathrm{~dB}$ & $-3.5 /-3.6$ & $90^{0}$ & $67 \%$ \\
\hline$[3]$ & $50 / 35.35 \Omega$ & - & - & $\begin{array}{c}-3.75 /- \\
3.85\end{array}$ & $90^{0}$ & $38 \%$ \\
\hline$[4]$ & $50 / 35.35 \Omega$ & $-30 \mathrm{~dB}$ & $-20 \mathrm{~dB}$ & $\begin{array}{c}-2.94 /- \\
3.72\end{array}$ & $90^{0}$ & $17.6 \%$ \\
\hline$[5]$ & $50 / 35.35 \Omega$ & - & - & $\begin{array}{c}-3.02 /- \\
3.48\end{array}$ & $90^{0}$ & - \\
\hline$[6]$ & $50 / 35.35 \Omega$ & $-10 \mathrm{~dB}$ & $-10 \mathrm{~dB}$ & $-3.2 /-3.7$ & $90^{0}$ & $13.9 \%$ \\
\hline$[7]$ & $50 / 35.35 \Omega$ & $-29.7 \mathrm{~dB}$ & - & $-3.6 /-3.9$ & $89.7^{0}$ & $73.2 \%$ \\
\hline
\end{tabular}




\begin{tabular}{|c|c|c|c|c|c|c|}
\hline$[8]$ & $50 / 35.35 \Omega$ & - & - & - & $90^{0}$ & $35.4 \%$ \\
\hline$[9]$ & $50 / 35.35 \Omega$ & $-25 \mathrm{~dB}$ & $-25 \mathrm{~dB}$ & - & $90^{0}$ & $54 \%$ \\
\hline$[10]$ & $50 / 35.35 \Omega$ & $-35 \mathrm{~dB}$ & $-35 \mathrm{~dB}$ & $\begin{array}{c}-3.75 /- \\
3.85\end{array}$ & $90^{0}$ & $63.9 \%$ \\
\hline
\end{tabular}

The performance results of various couplers design has been tabulated in above Table2. From the table we conclude that the coupler should attain $-3 \mathrm{~dB}$ power division in $\mathrm{S}_{21}, \mathrm{~S}_{31}$. The simulated $\mathrm{S}_{11}, \mathrm{~S}_{41}$ values should be better than $-10 \mathrm{~dB}$. Therefore the coupler should attain $90^{\circ}$ phase difference between the output ports[13].

\section{Conclusion:}

The design of various coupler design have been analyzed with different frequencies ranges from $1 \mathrm{GHz}$ to $2.5 \mathrm{GHz}$. Thus the coupler obtain $3 \mathrm{~dB}$ power division and 900 phase difference with its compact size. Therefore the coupler should provide good amplitude and phase imbalance and it attains maximum bandwidth.

\section{References}

[1] Jun He, Bing-Zhong Wang . Compact branch-line coupler with meander high-impedance transmission line and port impedance matching. The Journal of Engineering, Vol. 2016, Iss. 4, pp. 92-93, 22nd March 2016.

[2] Sudini Reshma and Mrinal Kanti Mandal.Miniaturization of a 90॰ Hybrid Coupler with Improved Bandwidth Performance. Vol. 26, No. 11, November 2016.

[3] YongqiangWang, Kaixue Ma .A Compact Branch-Line Coupler Using Substrate Integrated Suspended Line Technology. Vol. 26, No. 2, February 2016.

[4] B.F. Zong, G.M. Wang, C.X. Zhang and Y.W. Wang .Miniaturised branch-line coupler with ultra-wide high suppression stopband .Vol. 50 No. 19 pp. 1365-1367, 11th September 2014.

[5] C.-H. Tseng C.-H. Wu . Design of compact branch-line couplers using p-equivalent artificial transmission lines Vol. 6, Iss. 9, pp. 969-974 29th March 2012.

[6] Kai-Yu Tsai, Hao-Shun Yang .A Miniaturized 3 dB Branch-Line Hybrid Coupler With Harmonics Suppression.Vol. 21, No. 10, October 2011.

[7] W.-L. Chen G.-M. Wang . Exact design of novel miniaturised fractal-shaped branch-line couplers using phase-equalising method" Vol. 2, No. 8, pp. 773-780 25th April 2008.

[8] Ching-Wen Tang " Synthesizing Microstrip Branch-Line Couplers With Predetermined Compact Size and Bandwidth" Vol. 55, No. 9, September 2007.

[9] Ching-Wen Tang " Miniaturization of Microstrip Branch-Line Coupler With Dual Transmission Lines"Vol. 18, No. 3, March 2008.

[10] Jianpeng Wang, Bing-Zhong Wang .A Compact Slow-Wave Microstrip Branch-Line Coupler With High Performance" Vol. 17, No. 7, July 2007.

[11]B.Pavithra, S. Maheswari,"Design of Compact 180 degree Hybrid Coupler Using T-Shaped Structure" Advances in Engineering Research(AER), Volume No. 142, Pg. 248-251 -February 2018.

[12] Shirley Helen Judith , S. Maheswari .Miniaturization of microstrip Branchline Coupler for Wireless Application with branched TransmissionLines $.20183^{\text {rd }}$ International Conference on Communication and Ellectronics system . 15,16 October 2018.

[13] Indhumathi.J, S. Maheswari,.A Comparative Study of Various Microstrip Balun.2018 2nd International Conference for Phoenixes on Emerging Current Trends in Engineering And Management, March 2018. 